\title{
EDITORIAL
}

\section{Health Sector Reform Measures: Are they Working? .... And where do we go from Here?}

\section{Claudio Schuftan and Goran Dahlgren}

In many a health fora these days, scores of colleagues seem to be talking about Health Sector Reforms (HSRs). The questions that come up as a natural in the wane of this fervor are: What exactly are those HSRs that are being applied in developing countries? How have they been adapted to different local national realities? Are they working in the respective local national contexts in the developing world?

When trying to answer these questions, one has to be aware that generalizations --or the opposite: very particular, limited examples-- tend to caricaturize things; one cannot forget how vast and diverse the developing world is... Further, if one is tempted to say that these HSRs are working, then what is the tangible evidence for this? Conversely, if one is skeptical as we are, perhaps the time has come for us to be bold and to ask some hard additional questions.

It does not take a very critical attitude to say, in all honesty, that some of what is being proposed as HSR measures --including nutrition intervention packages-- are sometimes Structural Adjustment measures in disguise. They are often also just too complicated and are mostly too 'top-downish'. Other HSR measures call for major changes that are politically unsavory and take a strong determination to get under way. Getting started is so often such a problem that implementation plans tend to stay in the drawing board.

But more important --and overshadowing the above constraints-- is the fact that if one does not look at HSRs critically, one can easily miss the point that HSRs have really come to mean "market oriented interventions in the health and nutrition sector". The concept has literally been 'hijacked or monopolized' by what one could call a 'World Bank-led paradigm of health reforms'. It is thus of utmost importance to address the underlying assumptions being made about market-oriented HSRs as currently being aggressively promoted around the world. Without much analysis, it is contended that a more decisive market orientation of the existing public health sector will bring about increased efficiency. However, the evidence that market-oriented health care systems are more efficient than public health care systems is not even to be found in countries such as the US with its already highly market-oriented health care system. The very fact that almost twice as many financial resources (equivalent to $14 \%$ of the GNP) have to be used in the US to provide the same type and quality of care as Western European countries are providing (only spending $7-8 \%$ of their GNP) certainly indicates that great inefficiencies remain in the most market-oriented health care system in the world. One major reason for this is that it is still profitable to provide unnecessary care, another is that --in systems where private-for-profit health insurance companies play a major role-- the transaction costs (administration and other) are very high (in the order of 20-40\%). Consequently, even using pure traditional efficiency criteria, we need to be aware that evidence from many countries clearly indicates that public health care and nutrition systems can be, not only more equity-oriented, but also more efficient than market-oriented health care systems.

Of course, this does not imply that all public health care systems are efficient. The point we want to make is that inefficient public health care systems can indeed be made more efficient by improving relevant public policies and that, therefore, embracing a market orientation is not, by definition, the preferred way out to improve health care and nutrition for the people. Reforms being proposed to strengthen public health policies and public financing of health care via taxes are being gratuitously dismissed as supposedly being 'non-viable' as a realistic option for the future.

This dismissal is further reinforced by the theoretical contention by mainstream health economists that the role of government is 'to adjust the market failures' found in the health sector. The underlying assumption here is that a 'perfect market' --one with no failures-- will provide the best health care system. But this implies that demand, as expressed by purchasing power, should ultimately determine the supply and utilization of health care services; it is thus, by definition, impossible for a perfect market to provide health care services according to need -- 
regardless of ability to pay. Only if the groups with the greatest need for care would also be those with the most resources for buying the care they need would 'the market forces' be a possible regulator of access to care. But in reality, as seen in all countries, the opposite is the truth, i.e. the economically least privileged groups are the ones experiencing the greatest disease burden thus having the greatest need for care. If we yield to this reality --and our objective still is to provide health care according to need-- we are left with no choice but to look for ways to improve the public health care system, the one that can cater to the health and nutrition needs of those with less ability to pay.

This contention does not exclude a role for a parallel private for-profit health care sector that follows market forces primarily catering to the needs of the most privileged groups.

The main concern for HSRs must continue to be to secure quality health care services for the great majority of the population thus reducing social inequities in terms of economic, geographic and ethnic access to care. Consequently, we strongly feel that the focus of an equity oriented HSR has to be to gear scarce financial and skilled manpower resources to achieve this objective.

Within this conceptual framework, let us now review the shortcomings and future opportunities we see as they relate to the overall objective of developing an efficient, equity oriented HSR.

Risking some of the caricaturizing we warned against above, a number of truths on the shortcomings of HSRs (as currently being applied) HSRs can be found in some of the very bare-bone statements that follow:

- There is no evidence of current sustainable financing of health systems for the poor in the Third World without governments providing significant support.

- Government financing of the health and nutrition sector in developing countries is at best stagnating and, at worst, declining.

- Salaries of rural health personnel more often than not puts them at the threshold of poverty. Their technical skills are (sometimes grossly) out of date.

- Workshop-based training for them is mostly an income source and may increase their knowledge, but is not an effective approach to changing their practices.

- Health staff is sometimes involved in the private sale of drugs --most often non-essential drugs.

- The percentage of the population self-medicating has been increasing pretty much across the board.

- Uncontrolled drug sales by market vendors is on the rise.

- Essential drug programs are suffering as a consequence.

- Revolving drug funds have a nag for not fully revolving (if for no other reason or irregularity, because mark-ups do not cover the costs of the drugs or other treatments dispensed to patients being exempted), therefore, these funds slowly de-capitalize themselves.

- As the problems of access to PHC subside in many countries, we are facing a new threat: one that is making the established infrastructure's capacity to be underutilized (...or facilities being over-staffed in relative terms which is the other side of the same coin).

- The fee for service system is a form of regressive tax in which the poor pay as much as the non-poor. (High user fees for health are, at present, a major cause of pauperization of the near-poor).

- Becoming sick thus penalizes the poor more as disease becomes a greater economic burden for them than for the better-off, even when the fees are waived for the very poor.

- Private wards in public hospitals --supposed to subsidize the costs of care in adjacent public wards-- more often than not have ended up subsidizing the economically more privileged groups that use them.

- Short of deliberate government subsidies, prepayment schemes (health insurance) are not working for the poor and the rural population. (A consequence of this partial coverage of health insurance schemes is often that social inequities in access to health care increase as better-off groups with an insurance utilize public hospital services far more than their share).

- Equity in the provision of quality health care services is regressing, most probably both in the developing and developed countries in the world. 
- Governments have been slow or non-responsive to remedy most of the above (well known) situations hoping that a shift of the health sector towards a market orientation (including privatization) will solve the problem.

- Donors have not always reacted fast enough (or at all) to these shortcomings either, and there are renewed signs of donor fatigue.

The caveat here is that the perennial problem in the taking of decisions on all these issues is the limited involvement of the beneficiaries themselves!

One has to be aware that many of the strategies of health sector reform have been designed (mostly from the top) to specifically address a good number of the situations listed here (plus other). But providing what kind of solutions? Are most of them market-oriented solutions? If yes, how have they fared? If mixes of the above shortcomings still reflect the realities that besiege most developing countries, then the forced response to the latter question would be: so far, they have not fared so well... Then, it becomes crucial, of course, to qualify what this 'so far' means. Are countries applying new HSRs on the right track? And if so, is it just a matter of more time for things to turn around for the better?

The more radical corresponding hidden question obviously is: Is the HSRs agenda -- contents-wise, as well as operationally-- (already) in need of a face lift? Or, do most poor countries need a special (different) brand or package of HSRs.

Let it be understood here that there is nothing inherently wrong with market-oriented reforms in health, provided: - they work in the direction of greater efficiency and equity,

- they receive NO government subsidies, and

- they comply with well monitored regulations set-up upfront.

But these prerequisites hardly seem to exist anywhere at present --including countries with a 'socialist marketoriented' economy as are the cases of China and Vietnam...

The bottom line is that some important deep, structural changes need to be enforced to get reforms in the health and nutrition sector into a more sustainable track; such a track has to lead to the more urgently needed outcomes, especially those assuring minimum care and nutrition for the growing number of poor. Public hospital care, for example, has become unaffordable to the poor due to steep user fees. (Quite a few hidden costs add to this situation --'under the table payments' to doctors being just one type of them). Subsidizing such a system, instead of reforming it, will only channel additional funds to the wrong (non-poor) recipients.

HSRs can and have thus been used as crutches to pretend one is changing the system, but basically staying the course or even going backwards. Historically, there is a non-accidental link between SAPs, Adjustment with a Human Face and HSRs. The link is actually a progression, one with a calculated internal logic, namely to apply the principles of the market economy to the health sector.

The bottom line is that HSRs alone (as conceptualized and promoted in most of the current literature) cannot address a significant number of the structural constraints to equitable access to preventive, curative and rehabilitative health care and nutrition services faced by the poor. Not even with good targeting!

Furthermore, as currently being applied, HSRs use some technical terminology with misleading imprecision (or bias). Examples that come to mind are:

-"efficiency" (which is measured in economic terms only);

-"willingness to pay" (which is used in place of the much more real determinant, namely "ability to pay");

-"cost-sharing" (which is applied to regressive fee for service systems forgetting that general taxes have the potential of being a more progressive cost-sharing system when those who have more are made to pay more). The issue is thus not whether people should share the costs --because it is always them who end up paying anyway --the real issue is who is to pay more and who less or nothing. The point we want to make is that the 
terminology used is more and more linked to one specific ideological outlook (and thus type of HSR). But we do not want to go any deeper into this semantic issue at this time; we are aware the list is much longer.

So, what would be more effective and sustainable?

Perhaps the best response to a part of this question is in another question: Why not ask the beneficiaries directly to respond to this question?

This is not an evasive response! This response has the wisdom of --on top of so much that has already been said about it-- accepting the fact that:

- $\quad$ localized responses will (and should) be multiple and varied;

- there is not one response that fits all (or even many) diverse situations;

- our technical expertise can be put to a more effective use in a genuine (humble) dialogue with community representatives than in an (incestuous) technical dialogue among us as self-proclaimed experts;

- an all-encompassing wisdom is not necessarily a trade mark of communities (as so often is romantically implied): communities do not always know best (!), so mistakes will be made (but how many multimillion dollar mistakes have we technical people made... do we need to remind ourselves of that?);

- quickly learning from mistakes in an ongoing dialogue between communities and us professionals can lead to quicker sustainability than applying schemes imposed from outside, no matter how promising these look.

Paraphrasing Amartya Sen, our new Nobel laureate, he contends that in order to understand people's choices, one must know which alternatives are open to them in (the) real life. Such a grassroot-centered approach calls for an unprecedented change in our priorities and our modus operandus. The locus of control has to shift to beneficiaries for decisions that affect them directly on an everyday basis; and we ought to be instrumental in such a transition. At the same time, equity oriented measures have to be implemented from the central level. And that is the other part of the response to the question posed above. For the time being, and until the equity situation drastically changes for the better, some of the key elements of such reforms could be the following: (percentages are mostly illustrative and will change in each concrete context)

- Public rural health care services will still need to be primarily financed by governments (central and local).

- Governments should cover around $70-75 \%$ of total costs; only up to $10-15 \%$ can be realistically expected to be raised by community contributions or rural health insurance schemes; $5 \%$ can come from direct user fees, and an additional $10 \%$ perhaps from foreign aid.

- Financing public urban health care services will probably still need 50-60\% government financing; health insurance could cover around $30 \%$ of costs and user charges $15 \%$; the rest could come from foreign aid.

- Financing of health care will have to progressively move away from regressive fee for service schemes and towards prepayment schemes where the whole population --not only the sick-- contribute.

- Direct and indirect progressive taxes must, therefore, constitute the financial base in an efficient, equityoriented health care system. Government funds thus collected can then be used directly to fund public health services or can subsidize social health insurance schemes that will gradually cover the whole population.

- The issue of offering insured patients better care than to the general uninsured public is an issue that will need very careful analysis before a decision is made.

- If communities do contribute to the financing of health care services, they will have to have more de-facto control over how the funds are used.

- Governments will have to gradually reallocate resources from rich provinces/districts to poorer ones according to a set of needs-based indices and by then amending both recurrent and development central budgets accordingly. [Note that with the often growing presence of health insurance and user fee revenues, such reallocations will now have to take into account these revenues and add them to other financial resources invested by the government]. 
- General tax revenues that apply more to the rich (e.g., taxes on luxury items, spirits, tobacco, or on assets, estate and wealth) will have to be considered more seriously as a source to bring in financial resources from other sectors to the health sector.

- Health staff will have to become more accountable to local communities.

- The use of existing resources (human, material, organizational and financial) should be rationalized to better adapt them to actual needs. This will mean reallocating (or even shedding) personnel and mobilizing more resources to outreach work outside the health stations. All this should also be linked to medium term reforms that bring health staff income up to minimum standards of living preferably based on a system of monetary and non monetary incentives.

- The roots of the twin trend towards self-medication and underutilization of PHC facilities will have to be studied in each locality and ad-hoc measures taken with major inputs from the community itself; existing essential drug programs have to be made to work, but starting from the bottom up so as to make sure one is addressing people's felt needs at the base of their drug procurement/consumption/utilization behavior; drug companies (and clinical health staff...) have to be made to comply!

- Growth monitoring --an activity at the base of nutrition surveillance-- will have to move out from the health facilities to become community-based and more preventive and promotive in scope.

These are but a few of the central and local level options that merit being looked at more carefully again. But this listing is not the purpose of this review. The idea is that the process opening the doors to a more participatory and empowering dialogue (especially engaging women) has to come up with more of the answers and options. But for this to happen, said process has to be more decisively steered to a concrete departure and finishing line; and this is a task where health and nutrition professionals can help. This article is a wake up call.

One is left to wonder how many of the what one could call the more sustainable Equity-Oriented Health Sector Reform (EOHSR) measures quickly reviewed here have a chance of being seriously considered and implemented in the near future, even if it is on a pilot basis... The bottom line here is that we remain convinced that tinkering with the so far proposed HSRs will not do. That is the sad reality. Precious time is likely to be lost only to see the problems of inequity worsen.

We think that what is really needed is a 'HSR of the public health care sector', not one overwhelmingly in the direction of the private sector. The so often touted non-service-mindedness of the public sector is not a given. We need to fix a system that --granted-- has many flaws. But it also has many strong points! As its core is streamlined and strengthened, one can indeed contract out some ancillary services to the private sector --provided there is a fair system of competition in place. The new EOHSRs will explore these possibilities for improving the public sector in health and nutrition and keeping it at the core of a delivery system that can keep equity at the highest levels of priority. Because equity is so important to us --and in the absence of strong enough evidence to the contrary-- we ask ourselves why the latter option is flatly left out in mainstream HSR discussions and only more absolute market-oriented options are explored/proposed.

This brings us back full-circle to the old 'political will' issue which --we would like everybody to understand-- is not really an issue of "will" as such: it is an issue of "choice", of political choice. And being an issue of choice, for the time being --short of an awakening of civil society initiatives and movements in many places around the world at about the same time-- the responsibility to move towards EOHSRs is still squarely back on the lap of the respective governments. Much advocacy and lobbying, as well as opposition to powerful internal and external forces, are still needed in order to put the last first....

(This editorial reflects solely the personal views of the authors, and not of the Journal and persons and institutions associated with it.) 